\title{
Author Correction: Representation of molecular structures with persistent homology for machine learning applications in chemistry
}

\author{
Jacob Townsend, Cassie Putman Micucci (D), John H. Hymel (D, Vasileios Maroulas (D) \& \\ Konstantinos D. Vogiatzis (1)
}

Correction to: Nature Communications https://doi.org/10.1038/s41467-020-17035-5, published online 26 June 2020.

In the original version of this article, some text was missing from the legends of Figure 5 and Figure 6.

The legend of Figure 5 originally read:

" $\mathrm{CO}_{2}$ interaction energy distribution shown as horizontal violin plots for the first, second, and third active-learning steps. The height of the shape shows the frequency of occurrences.."

The correct version states:

" $\mathrm{CO}_{2}$ interaction energy distribution shown as horizontal violin plots for the first, second, and third active-learning steps. a CM, b BoB, c SOAP, and d PI. The height of the shape shows the frequency of occurrences..."

This has been corrected in both the PDF and HTML version of the article.

The legend of Figure 6 originally read:

"Predicted $\mathrm{CO}_{2}$ and $\mathrm{N}_{2}$ interaction energies (in $\mathrm{kcal} \mathrm{mol}^{-1}$ ) for all molecules in the GDB-9 database using four molecular representation models. Only the model that utilized the PI molecular representation ..."

The correct version states:

"Predicted $\mathrm{CO}_{2}$ and $\mathrm{N}_{2}$ interaction energies (in $\mathrm{kcal} \mathrm{mol}^{-1}$ ) for all molecules in the GDB-9 database using four molecular representation models. a CM, b BoB, c SOAP, and d PI. Only the model that utilized the PI molecular representation."

This has been corrected in both the PDF and HTML version of the article.

Published online: 14 July 2020

Open Access This article is licensed under a Creative Commons Attribution 4.0 International License, which permits use, sharing, adaptation, distribution and reproduction in any medium or format, as long as you give appropriate credit to the original author(s) and the source, provide a link to the Creative Commons license, and indicate if changes were made. The images or other third party material in this article are included in the article's Creative Commons license, unless indicated otherwise in a credit line to the material. If material is not included in the article's Creative Commons license and your intended use is not permitted by statutory regulation or exceeds the permitted use, you will need to obtain permission directly from the copyright holder. To view a copy of this license, visit http://creativecommons.org/licenses/by/4.0/. 